có ý nghĩa thống kê với $p<0,05$. Điều này có thể hiểu rằng, những người cao tuổi trước đây là cán bộ công chức thì họ có mối quan hệ xã hội cũng như kiến thức nhất định liên quan đến việc cần chăm lo sức khỏe cũng như độc lập, tự chủ về tài chính do đó họ thường biết tự quyết định các giải pháp chăm lo cá nhân của bản thân được tốt hơn so với nhóm đối tượng còn lại ở các ngành nghề khác.

Một nội dung được ghi nhận thông qua nghiên cứu này nên đáng được quan tâm hơn để góp phần có giải pháp phát triển bất kỳ loại hình dịch vụ mới nào, không riêng dịch vụ vè y tế, đó là khách hàng cần được nắm các thông tin liên quan đến dịch vụ mình sẽ sử dụng, từ đó nhu câu sử dung sẽ được tăng cao hơn. Do vây, với nghiên cứu này cũng ghi nhận được rằng nhóm người cao tuổi đã từng nghe về dịch vụ chăm sóc ban ngày có nhu cầu sử dụng dịch vụ này cao hơn gấp 4 lần so với nhóm người cao tuổi còn lại (lần lượt là $80,0 \%$ và $20,0 \%$ ), sự khác biệt này có ý nghĩa thống kê với $p<0,05$. Tương tự, như kết luận của nghiên cứu về nhu cầu sử dụng dịch vụ y tế mới - dịch vụ chăm sóc sức khỏe từ xa [8].

\section{KẾT LUÂN}

Nghiên cứu chỉ ra nhu cầu sử dung dich vu chăm sóc nội trú ban ngày sẽ được chú ý và quan tâm hớn khi người dân hiểu rõ hơn về dịch vụ này, đồng thời dịch vụ này cũng sẽ có nhiều khả năng được quan tâm hơn ở những đối tượng có điều kiện về kinh tế. Do vậy, để phát triển các dịch vụ y tế mới trong đó có dịch vụ chăm sóc nội trú ban ngày cho người cao tuổi, cần tăng cường công tác tuyên truyên, quảng bá về loại hình dịch vụ này đến đông đảo người dân và cộng đồng, tập trung ưu tiên nhóm đối tượng có mức kinh tế cao.

\section{TÀI LIẸU THAM KHẢO}

1. Cục thống kê thành phố Đà Nẵng (2020), Niền giám thống kê năm 2019 trên địa bàn thành phố Đà Nẵng.

2. European Telemedicine

Lung Foundation

(2019),

3. Định nghĩa về chăm sóc ban ngày - Daycare, đăng tảai tại link: https://www.msdmanuals.com

4. Nguyển Thị Bảo Ai và cộng sự (2020), Nghiên cứu đặc điểm và nhu cầu chăm sóc bệnh mạn tính ở người cao tuổi tại thành phố Quy Nhợn, tỉnh Bình Đijnh năm 2020.

5. Nguyê̂n văn Sai (2014), Thực trang sức khỏe và nhu cầu chăm sóc y tế của người cao tuổi tại hai huyện tỉnh Hải Dương năm 2013.

6. Trân Thì Hanh (2008). Thực trang chăm sóc sức khỏe tại nhà cho người cao tuổi quận Ô Môn TP. Cần Thớ.

7. Bùi Thùy Dương (2010), Khảo sát nhu câu chăm sóc sức khở ngoài giớ và tại nhà của bệnh nhân và người nhà bênh nhân đến khám bệnh tại Bệnh viện Đại học Y Hà Nội năm 2010.

8. Quách Hữu Trung, Võ Thị Hồng Hướng và cộng sự, Kiến thức và nhu câu về sứ dụng dịch vụ khám chữa bệnh từ xa của bênh nhấn đái tháo đường tại thành phố Đà Nẵng năm 2021.

\title{
YẾU Tố ẢNH HƯỞNG ĐẾN SỬ DƯNG VANCOMYCIN AN TOÀN VÀ HIÊ̂U QUẢ TRONG ĐIỀU TRỊ NHIỄM KHUẨN NẶNG TRẺ EM
}

\section{TÓM TẮT}

Mục tiêu: Khảo sát các yếu tố ảnh hưởng đến sử dung an toàn và hiệu quả của vancomycin trong điều trị nhiễm trùng nặng trẻ em. Phương pháp tiến hành: Nghiên cứu cắt ngang mô tả các bệnh nhân trẻ em được chỉ định điều trị vancomycin trên 3 ngày. Các trường hợp này được đo nồng đô đáy vancomycin và độ thanh thải creatinin để theo dõi hiệu quả và an toàn của sử dung vancomycin. Kết quả: Nghiên cứu thu nhận 40 trường hợp. Liều lượng vancomycin sử

\footnotetext{
${ }^{1}$ Đại học Y Dược Thành phố Hồ Chí Minh 2Bềnh viện Nhi Đồng 2

Chịu trách nhiệm chính: Hà Mạnh Tuấn

Email: hamanhtuan@ump.edu.vn

Ngày nhận bài: 16.3.2021

Ngày phản biên khoa hoc: 12.5.2021

Ngày duyệt bài: 21.5.2021
}

\section{Hà Mạnh Tuấn ${ }^{1}$, Kim Trần Quan²}

dung trung bình là $55,83 \pm 19,34 \mathrm{mg} / \mathrm{kg} / \mathrm{ngày}$. Nồng độ đáy vancomycin trung vị là $11,09(7,84-16,46)$ $\mu \mathrm{g} / \mathrm{ml}$. Độ thanh thải creatinin trung bình là $80,18 \pm$ $29,14 \mathrm{ml} / \mathrm{min}$. Các yếu tố ảnh hưởng đến sử dụng vancomycin an toàn và hiệu quả là liều lượng vancomycin, cách sử dụng vancomycin và độ thanh thải creatinin. Kết luân. Cần xem xét điều chỉnh liều lượng vancomycin, cách sử dụng vancomycin theo độ thanh thải và nồng đô đáy vancomycin để đảm bảo tính an toàn và hiệu quả trong điều trị.

\section{SUMMARY}

FACTORS AFFECTING THE SAFE AND EFFECTIVE USE OF VANCOMYCIN IN TREATMENT OF SEVERE INFECTIONS IN CHILDREN

Objectives: To investigate the factors affecting the safe and effective use of vancomycin in the treatment of severe infections in children. Methods: 
A descriptive cross-sectional study was conducted in pediatric patients who indicated vancomycin for more than 3 days. Trough vancomycin levels and creatinine clearance were measured to monitor the efficacy and safety of vancomycin use in these cases. Results: The study enrolled 40 cases. The average dose of vancomycin used was $55.83 \pm 19.34 \mathrm{mg} / \mathrm{kg} /$ day. The median trough vancomycin concentration was 11.09 $(7.84-16.46) \mu \mathrm{g} / \mathrm{ml}$. The mean creatinine clearance was $80.18 \pm 29.14 \mathrm{ml} / \mathrm{min}$. Factors influencing the safe and effective use of vancomycin were vancomycin dose, way of vancomycin administration, and creatinine clearance. Conclusion: It is necessary to consider adjusting the dose of vancomycin, the way of vancomycin use according to creatinine clearance and trough vancomycin concentration to ensure safety and effectiveness in treatment.

Keywords: trough concentration; vancomycin; children.

\section{I. Đă̆T VẤN ĐỀ}

Hiện nay vancomycin là kháng sinh chính trong điều trị các nhiếm trùng nặng do vi khuẩn gram dương ở trẻ em, nhất là các trường hợp nhiễm khuẩn nặng do tụ cầu kháng methicilline (methicillin-resistant Staphylococcus aureusMRSA). Hiệu quả điều trị của vancomycin phụ thuộc vào nồng độ vancomycin trong huyết thanh. Để xác định nồng độ điều trị của vancomycin trong huyết thanh ở trẻ em, Hiệp hội Bệnh nhiễm khuẩn Hoa Kỳ (Infectious Diseases Society of America - IDSA) khuyến cáo sử dụng nồng độ đáy của vancomycin đo vào 5 giờ sau khi tiêm vancomycin liều thứ ba để đánh giá nồng độ vancomycin hiệu quả trong điều trị. Mức nồng độ đáy cân đạt được theo khuyến cáo IDSA là là $15-20 \mu \mathrm{g} / \mathrm{ml}$ để đảm bảo hiệu quả và an toàn của vancomycin trong điều trị [1]. Nồng độ đáy vancomycin đích cần đạt phụ thuộc vào nhiều yếu tố như: liều vancomycin, cách dùng vancomycin, độ lọc cầu thận, và một số yếu tố khác [2]. Nghiên cứu này được thực hiện với mục tiêu khảo sát các yếu tố ảnh hưởng đến sử dụng an toàn và hiệu quả của vancomycin nhằm giúp cho việc sử dụng vancomycin trong điều trị nhiễm khuẩn nặng ở trẻ em tốt hơn.

\section{II. ĐỐI TƯỢNG VÀ PHƯƠNG PHÁP NGHIÊN CỨU \\ Thiết kế nghiên cứu và tiêu chuẩn chọn}

bênh. Nghiên cứu mô tả cắt ngang đước tiến hànhh tại khoa Nhiễm của bệnh viện Nhi Đồng trong thời gian từ tháng $3-6 / 2020$. Các bệnh nhân dưới 15 tuổi nhập viện chỉ định điêu trị với vancomycin ít nhất 3 ngày và được sự đồng thuận của thân nhân bệnh nhân. Các trường hợp có tổn thương thận cấp tính với mức creatinine huyết thanh $>2 \mathrm{mg} / \mathrm{dL}$, huyết động học không ổn định hay dị ứng với vancomycin sẽ không nhận vào nghiên cứu. Cỡ mẫu là lấy trọn tất cả các trường hợp đủ tiêu chuẩn trong thời gian nghiên cứu.

Tiến hành nghiên cứu. Các bệnh nhân nghiên cứu sẽ được ghi nhận các thông tin theo phiếu thu thâp dữ liệu. Tẩt cả bệnh nhân đều được lấy mẫu máu và các dịch tương ứng để xác định tác nhân gây bệnh. Nồng độ đáy của vancomycin được đo bằng các lấy mẫu máu 5 giờ sau tiêm vancomycin liều thứ ba và 30 phút trước liều vancomycin thứ tư. Nồng độ đáy vancomycin được đo bằng máy ARCHITECT $\mathrm{i}$ System với phướng pháp hóa quang miễn dịch vi thể (chemiluminescent microparticle immunoassay - CMIA) theo protocol STAT. Độ thanh thải creatinin được tính theo công thức Schwartz.

Xử lý thống kê. Các biến số định tính được mô tả bằng tần số và tỉ lệ phần trăm; biến số định lượng được mô tả bằng trung bình và độ lệch chuẩn (nếu phân phối chuẩn) hay trung vị và khoảng tứ phân vị (nếu phân phối không chuẩn). Phép kiểm t dùng để so sánh hai trung bình, phép kiểm Man-Whitney dùng kiểm định các biến phi tham số. Tương quan Pearson đùng để khảo sát mối tương quan của hai biến liên tục. Giá trị $p<0,05$ thì được xem là có ý nghĩa thống kê. Các số liệu được xử lý bằng phần mềm SPSS 20.0.

\section{KẾT QUẢ NGHIÊN CỨU}

Có tất cả 40 trường hợp đủ tiêu chuẩn được đưa vào nghiên cứu với các đặc điểm được trình bày trong bảng 1 . Các trường hợp này đều có chỉ định sử dụng vancomycin với thời gian sử dụng dự kiến ít nhất trên 3 ngày và phù hợp với chẩn đoán lâm sàng. Có $65 \%$ trường hợp được phân lập ra vi khuấn trên ít nhất một mẫu bệnh phẩm, chủ yếu là Staphylococcus spp. Tất cả đều được đo lường độ thanh thải creatinin trước khi chỉ định dùng vancomycin với độ thanh thải trung bình là $80,18 \pm 29,14(\mathrm{ml} / \mathrm{min})$. Liều vancomycin sử dụng trung bình là $55,83 \pm 19,34$ ( $\mathrm{mg} / \mathrm{kg} / \mathrm{ngày}$ ) là liều lượng phù hợp với chỉ định của trẻ em theo lý thuyết.

Bảng 1. Đặc điểm của bệnh nhân nghiên cứtu

\begin{tabular}{|c|c|c|}
\hline Đặc điểm & $\begin{array}{c}\text { Tân số } \\
(n=40)\end{array}$ & $\begin{array}{l}\text { Tý lế } \\
(\%)\end{array}$ \\
\hline Giới: & 25 & 62,5 \\
\hline Nũ & 15 & 37,5 \\
\hline Tuối * & \multicolumn{2}{|c|}{$1,4(0,4-8,5)$} \\
\hline$\leq 1$ tháng & 4 & 10,0 \\
\hline 1 tháng - 12 tháng & 13 & 32,5 \\
\hline
\end{tabular}


VIETNAM MEDICAL JOURNAL N ${ }^{0} 1$ - JUNE - 2021

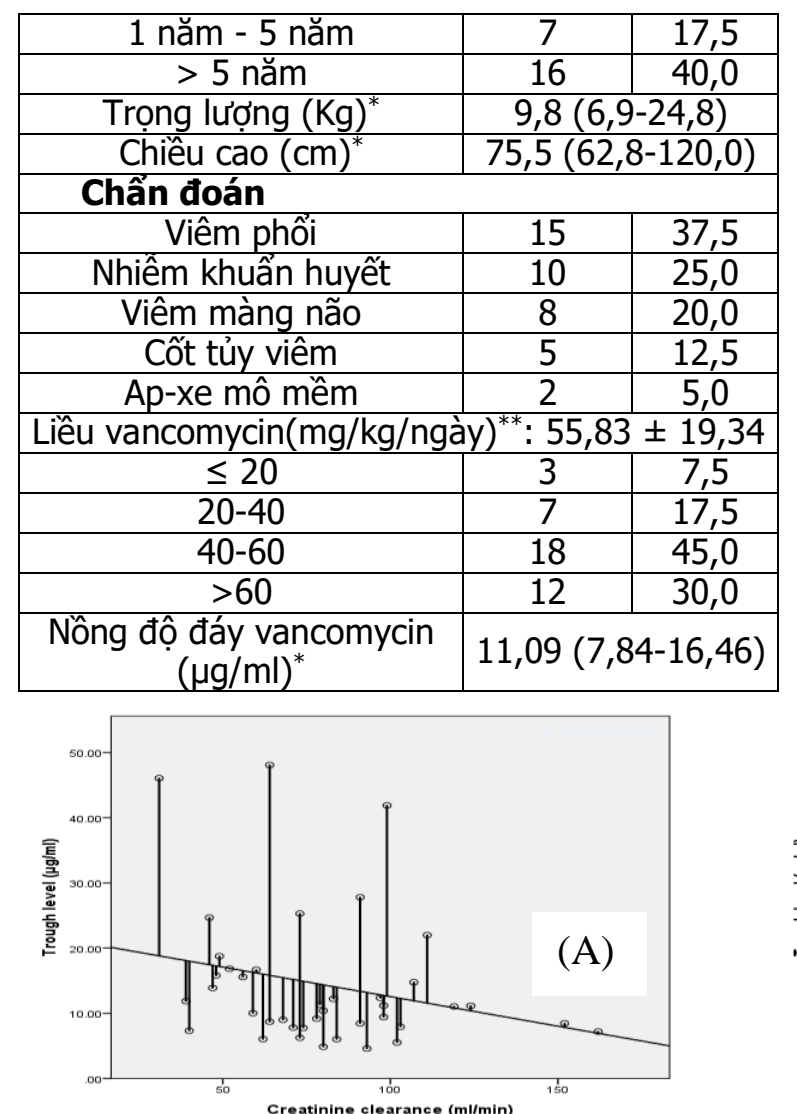

\begin{tabular}{|c|c|c|}
\hline$\leq 5$ & 2 & 5,0 \\
\hline $5-10$ & 15 & 37,5 \\
\hline $10-15$ & 11 & 27,5 \\
\hline $15-20$ & 5 & 12,5 \\
\hline$>20$ & 7 & 17,5 \\
\hline $\begin{array}{l}\text { Độ thanh thải creatinine } \\
\qquad(\mathrm{ml} / \mathrm{min})^{* *}\end{array}$ & \multicolumn{2}{|c|}{$80,18 \pm 29,14$} \\
\hline$\leq 30$ & 0 & - \\
\hline $30-60$ & 11 & 27,5 \\
\hline $60-90$ & 14 & 35,0 \\
\hline$>90$ & 15 & 37,5 \\
\hline Vi khuấn phân lập & 26 & 65,0 \\
\hline S. aureus & 14 & 35,0 \\
\hline S. epidermidis & 8 & 20,0 \\
\hline Streptococcus spp & 4 & 10,0 \\
\hline
\end{tabular}

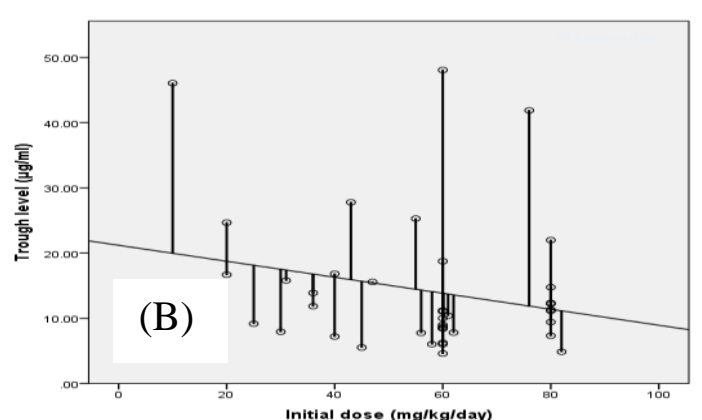

Hình 1. Liên quan giữa liêu van comycin sử dụng, nồng độ đáy của vancomycin, và độ thanh thải creatinin. (A) Liên quan giữa nồng độ đáy và liều vancomycin sử dụng;

(B) Liên quan giữa nông độ đáy và độ thanh thải creatinin.

Hình 1 cho thấy có mối liên quan giữa liều vancomycin sử dụng, nồng độ đáy của vancomycin và độ thanh thải creatinin. Nồng độ đáy của vancomycin không có mối liên quan có ý nghĩa thống kê với liêu vancomycin sử dụng $\left(r^{2}\right.$ $=-0.224 ; \mathrm{p}=0.164 ; 95 \% \mathrm{CI}:-0.597-0.151)$ và độ thanh thải creatinin $\left(r^{2}=-0.250 ; p=\right.$ $0.120 ; 95 \%$ CI: $-0.493-0.044)$. Có sự khác biệt về tỷ lệ nồng độ đáy vancomycin đạt được mức đích so với liêu vancomycin sử dụng, chỉ có $33 \%$ các trường hợp liều sử dụng vancomycin $\leq 20$ $\mathrm{mg} / \mathrm{kg} / \mathrm{ngày}$ đạt mức hiệu quả $(15-20 \mu \mathrm{g} / \mathrm{ml})$, $57,1 \%$ với liêu sử dụng từ $20-40 \mathrm{mg} / \mathrm{kg} / \mathrm{ngày,}$ $27,8 \%$ với liều từ $40-60 \mathrm{mg} / \mathrm{kg} / \mathrm{ngày} \mathrm{và} 41,7 \%$ với liều $>60 \mathrm{mg} / \mathrm{kg} / \mathrm{ngày}$ (hình 2 ).

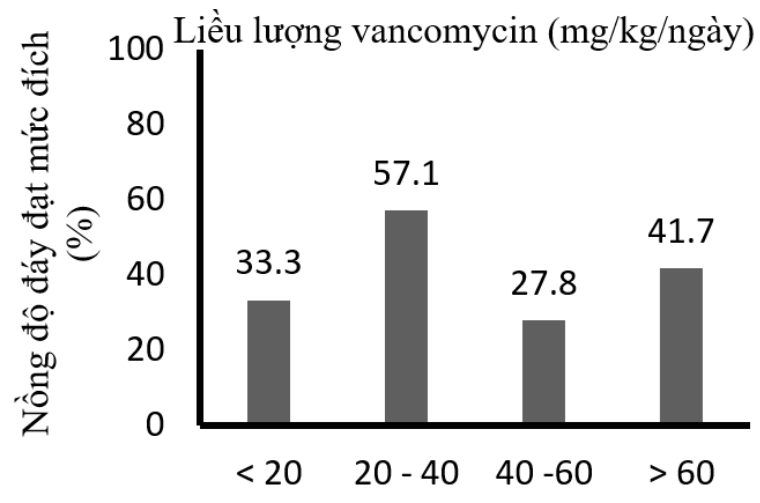

Hình 2. Liều vancomycin sử dụng và mức đạt nồng độ đáy vancomycin đích

Bảng 2. Liều sử dụng, liều hiệu chỉnh và nồng độ đáy theo độ thanh thải creatinin

\begin{tabular}{|c|c|c|c|c|}
\hline \multirow{2}{*}{ Vancomycin } & \multicolumn{3}{|c|}{ Độ thanh thải creatinin (ml/min) } & \multirow[b]{2}{*}{$\mathrm{p}$} \\
\hline & $30-60$ & $60-90$ & $>90$ & \\
\hline $\begin{array}{c}\text { Liều sứ dụng (mg/kg/day) } \\
\text { (mean } \pm \mathrm{SD})\end{array}$ & $40,0 \pm 20,6$ & $61,4 \pm 13,9$ & $62,3 \pm 16,9$ & 0,004 \\
\hline $\begin{array}{l}\text { Nồng độ đáy }(\mu \mathrm{g} / \mathrm{ml}) \\
\text { (median - IQR) }\end{array}$ & $\begin{array}{c}15,80 \\
(11,85-18,75)\end{array}$ & $\begin{array}{c}8,85 \\
(6,25-11.30)\end{array}$ & $\begin{array}{c}11,04 \\
(7,93-14,76)\end{array}$ & 0,406 \\
\hline
\end{tabular}




\begin{tabular}{|c|c|c|c|c|}
\hline $\begin{array}{c}\text { Liều hiệu chỉnh (mg/kg/day) } \\
(\text { mean } \pm \text { SD) }\end{array}$ & $40,0 \pm 37,1$ & $89,6 \pm 48,6$ & $75,0 \pm 35,6$ & 0,016 \\
\hline
\end{tabular}

Kết quả từ bảng 2 cho thấy liều vancomycin sử dụng và liều vancomycin hiệu chỉnh sau khi có nồng độ đáy trong các nhóm có độ thanh thải creatinin khác nhau có sự khác biệt có ý nghĩa thống kê $(p<0,05)$ (bảng 2); nhưng không có sự khác biệt có ý nghĩa thống kê về nồng độ đáy đo được giữa các nhóm có độ thanh thải creatinin khác nhau $(p>0,05)$. Nghiên cứu cũng ghi nhận mặc dầu liêu vancomycin sử dụng cao nhưng bệnh nhân có độ thanh thải creatinin cao > 60 $\mathrm{ml} / \mathrm{min}$ thì nồng độ đáy cũng không đạt được mức đích, trong khi đó liêu vancomycine thấp nhưng độ thanh thải creatinin thấp thì nồng độ đáy vẫn có thể đạt mức đích. Liều vancomycin hiêu chỉnh sẽ cao hơn liều vancomycin sử dụng rất nhiêu nếu nồng độ đáy đạt mức thấp (bảng 2).

\section{BÀN LUÂN}

Vancomycin là thuốc kháng sinh thiết yễu trong điều trị các nhiễm khuẩn gram dương nặng ở trẻ em hiện nay nhất là trong tình hình kháng thuốc đang gia tăng. Hiệu quả điều trị của vancomycin phụ thuộc vào nồng độ hiêu quả của vancomycin trong máu, nếu không đủ nồng độ hiệu quả điều trị thì kết quả sẽ kém và gia tăng tình hình kháng thuốc. Tuy nhiên tác dụng có hại như độc thận và tai của vancomycine cũng rất thường xảy ra nếu dùng vancomycin liều cao. Chính vì thế cần phải theo dõi nồng độ hiệu quả của vancomycin thông qua nồng độ đáy của vancomycin theo như khuyến cáo của IDSA [1] và tìm hiểu những yếu tố ảnh hưởng đến nồng độ đáy để giúp cho việc sử dụng vancomycin an toàn và hiệu quả hơn.

Liều lượng vancomycin trong nghiên cứu này trung bình là $55,83 \mathrm{mg} / \mathrm{kg} / \mathrm{ngày}$ với giả định là đạt được hiệu quả lâm sàng. Tuy nhiên nồng độ đáy đo được trung vị là $11,09 \mu \mathrm{g} / \mathrm{ml}$ là thấp hơn so với nồng độ đáy hiệu quả theo khuyến cáo của IDSA là $15-20 \mu \mathrm{g} / \mathrm{ml}$ cho điều trị các trường hợp nhiễm khuẩn nặng và chỉ có $12,5 \%$ các trường hợp là đạt được nồng độ hiệu quả. Tỷ lệ này vẫn còn cao hơn so với nghiên cứu của Chang và cộng sự trong một nghiên cứu 50 bệnh nhi được sử dụng vancomycin với liều 40 - 60 $\mathrm{mg} / \mathrm{kg} / \mathrm{ngày}$ chỉ có $4 \%$ đạt được nồng độ đáy đích [3]. Phát hiện này cũng được ghi nhận trong nhiều nghiên cứu khác $[2,3,4]$. Điều này có thể giải thích do đắc tính dược động học của vancomycin thay đổi theo tuổi bệnh nhân, ngoài ra độ thanh thải vancomycine của trẻ em nhanh hơn người lớn 2 - 3 lần [5]. Như vậy liều vancomycin chỉ định như lý thuyết cho trẻ em có thể vẫn chưa đạt hiệu quả điều trị mong muốn.

Nghiên cứu này ghi nhận độ thanh thải creatinin có liên quan nghịch đến đến nồng độ đáy của vancomycin $(r=-0,250)$, mặc dầu chưa có ý nghĩa thống kê nhưng cũng cho thấy có mối liên quan ở mức độ nào đó. Điều này có thể giải thích do thân là cơ quan chính để thải vancomycin vì thế nồng độ đáy của vancomycin sẽ phụ thuộc vào độ lọc cầu thận và độ thanh thải creatinin $[3,5]$. Chính vì thể trong điêu trị với vancomycin cần phải theo dõi đô thanh thải creatinin để có thể điều chỉnh liều phù hợp tránh gây các biến cố bất lợi do quá liều vancomycin nhất là thận và tai.

Nghiên cứu này không ghi nhận sự tương quan thuận giữa liều lượng vnacomycin và nồng độ đáy đo được. Có sự khác biệt về tỷ lệ các trường hợp có nồng độ đáy vancomycin đạt hiệu quả điêuu trị so với liều lượng vancomycin sử dụng. Điều này cũng được ghi nhận trong các nghiên cứu trước đây $[3,4]$. Sự khác biệt này được giải thích là do sự khác biệt về liều tải của vancomycin và khoảng cách giữa các liêu vancomycin sử dụng và do đặc tính dược động học của vancomycin khác nhau giữa các cá nhân. Trẻ em có thời gian bán hủy của vancomycin ngắn hơn (2 - 3 giờ) so với người lớn (5 -11 giờ) [3]. Ngoài ra thời điểm lấy mẫu máu để đo lường nồng độ đáy cần phải phù hợp, nếu lấy quá sớm hay quá muộn so với hướng dẫn 5 giờ sau liều thứ ba có thể đưa đến kết quả không đúng [6].

Tữ những phân tích trên cho thấy với liều vancomycine theo lý thuyết là $40-60 \mathrm{mg} / \mathrm{kg} / \mathrm{ngày}$ ở trẻ em không tạo ra nồng độ vancomycin trong huyết thanh đạt hiệu quả điều trị. Điều này cũng được ghi nhận trong các nghiên cứu về liều lượng của vancomycin trong điều trị nhiễm trùng nằng cho trẻ em $[3,4]$. Nhiêu chuyên gia đề nghị liều vancomycin cao hơn cho trẻ em trong điều trị các nhiễm trùng nặng [4]. Tuy nhiên cần phải xem xét việc điều chỉnh liều này toàn diện hơng vì nguy cơ các tác dụng có hại, nhất là độc tính do thận khi dùng vancomycin liều cao. Vì vậy việc theo dõi nồng độ vancomycin trong quá trình điểu trị là hết sức cần thiết để đảm bảo đạt hiệu quả điều trị đồng thời giảm thiểu thấp nhất nguy cơ tác dung có hai do thuốc.

Nghiên cứu này cũng có một số hạn chế. Trước hết là số ca còn ít, kế đến dữ liệu về liều tải và khoảng cách các liều trong nghiên cứu 
chưa được ghi nhận và cuối cùng nồng độ đáy của vancomycin và độ thanh thải của creatinin chưa được đánh giá lại sau điều chỉnh liêu vancomycin do nghiên cứu là mô tả cắt ngang. Các nghiên cứu thêm cần được tiến hành để đánh giá tính hiệu quả và an toàn khi điều chỉnh liều vancomycin theo nồng độ đáy và độ thanh thải creatinin.

\section{KẾT LUÂ̂N}

Cần phải xem xét điều chỉnh liêu vancomycin, cách sử dụng vancomycin theo nồng độ đáy và độ thanh thải creatinin để đảm bảo an toàn và hiệu quả trong điều trị vancomycin cho các trường hợp nhiểm khuẩn nặng ở trẻ em.

\section{TÀI LIÊU THAM KHẢO}

1. Rybak, M., et al., Therapeutic monitoring of vancomycin in adult patients: a consensus review of the American Society of Health-System Pharmacists, the Infectious Diseases Society of America, and the Society of Infectious Diseases
Pharmacists. Am J Health Syst Pharm, 2009. 66(1): p. 82-98.

2. Tongsai, S. and P. Koomanachai, The safety and efficacy of high versus low vancomycin trough levels in the treatment of patients with infections caused by methicillin-resistant Staphylococcus aureus: a metaanalysis. BMC Res Notes, 2016. 9(1): p. 455.

3. Chia Ning Chang, W.T.L., Ming Chin Chan, Chih Chien Wang, A Retrospective Study to Estimate Serum Vancomycin Trough Concentrations in Pediatric Patients with Current Recommended Dosing Regimen. Journal of Medical Sciences, 2018. 38: p. 275-279.

4. Frymoyer, A., et al., Current recommended dosing of vancomycin for children with invasive methicillin-resistant Staphylococcus aureus infections is inadequate. Pediatr Infect Dis J, 2009. 28(5): p. 398-402.

5. Rajon, K., et al., Vancomycin use, dosing and serum trough concentrations in the pediatric population: a retrospective institutional review. Pharm Pract (Granada), 2017. 15(2): p. 887.

6. Dolan, E., et al., Effect of Vancomycin Loading Doses on the Attainment of Target Trough concentrations in Hospitalized Children. J Pediatr Pharmacol Ther, 2020. 25(5): p. 423-430.

\section{MộT Số YẾU TỐ LIÊN QUAN ĐẾN NĂNG LƯỢ'NG KHẨU PHẦN ĂN CỦA NGƯỜI BÊ̂NH UNG THƯ TẠI BỆNH VIỆN QUÂN Y 103}

\section{TÓM TẮT}

Mục tiêu: đánh giá tình trạng dinh dưỡng và khẩu phân ăn của người bệnh ung thư. Phương pháp: Nghiên cứu mô tả cắt ngang trên 212 người bệnh ung thư điều trị nội trú tại Trung tâm Ung bướu và Y học hat nhân Bệnh việ Quân y 103 năm 2019. Kết quả: tình trang SDD bằng các phương pháp cho thấy SDD ở người bênh ung thư chiếm tỷ lệ cao: PG-SGA (91\%); BMI $(34,4 \%)$, Lympho $(27,8 \%)$, Hemoglobin $(25,9 \%)$, Albumin huyết thanh $(6,1 \%)$. Năng lượng trung bình từ KPA hàng ngày của $\mathrm{BN} K(1,627.7 \mathrm{Kcal})$ thấp hơn so với nhu cầu khuyến nghị trung bình $(1,848.0 \mathrm{Kcal})$. Tỷ lệ đạt nhu câuu năng lượng khuyến nghị cho BN K chì đạt $25,9 \%$. Các đặc điểm thay đổi chế độ ăn thường gặp là: giảm khẩu phần ăn (75\%), chỉ ăn được thực phẩm lỏng $(17,9 \%)$ hoăc ăn rất ít $(2,4 \%)$. Nhóm tuổi <60 không đạt năng lượng khẩu phần ăn 24h $(O R=2,06 ; p<0,05)$ cao hơn nhóm $>60$, nam giới không đạt năng lượng khẩu phần ăn $24 \mathrm{~h}$ $(\mathrm{OR}=2,03 ; p<0,05)$ và không đạt lượng Protein khẩu phần ăn 24h $(O R=2,14 ; p<0,05)$ cao hơn nữ giới. Không có liên quan giữa giai đoạn ung thư với năng

*Bênh viên quân y 103/ Học viện Quân y

Chịu trách nhiệm chính: Phạm Đức Minh

Email: ducminh.pham@vmmu.edu.vn

Ngày nhận bài: 12.3.2021

Ngày phản biên khoa học: 14.5.2021

Ngày duyệt bài: 21.5.2021

\section{Phạm Đức Minh*, Tạ Việt Hà*}

lượng khẩu phần ăn ( $p>0,05)$. Kết luận: Tình trạng SDD phổ biến ở người bệnh ung thư, tỷ lệ thấp đạt nhu câu năng lượng, có liển quan giữa tuổi và giới với năng lượng khẩu phần ăn.

Tư khóa: Tình trạng dinh dương, ung thư, PG - SGA.

\section{SUMMARY}

\section{ASSOCIATED FACTORS TO DIETARY ENERGY IN CANCER PATIENTS IN MILITARY HOSPITAL 103}

Objectives: to assess nutritional status and dietary intake of cancer patients. Methods: cancer patients inpatient treatment at the Center for Oncology and Nuclear Medicine 103 Military Hospital. Results: Assessment by different methods showed that malnutrition in cancer patients accounted for a high percentage: PG-SGA (91\%); BMI (34.4\%), Lymphocyte $(27.8 \%)$, Hemoglobin (25.9\%), Serum Albumin $(6.1 \%)$. The average daily caloric intake of BN K $(1,627.7 \mathrm{Kcal})$ was lower than the average recommended requirement $(1,848.0 \mathrm{Kcal})$. The rate of passing recommended energy requirements for patients with cancer was only $25.9 \%$. The most common dietary changes were: reduced portion sizes $(75 \%)$, only liquid foods $(17.9 \%)$ or very little $(2.4 \%)$. The age group $<60$ did not get the energy of the $24 \mathrm{~h}$ diet $(O R=2.06 ; p<0.05)$ higher than the group $>60$, the men did not get the energy of the $24 \mathrm{~h}$ diet $(O R=2.03 ; p<0.05)$ and did not reach the 24h dietary protein intake $(\mathrm{OR}=2.14 ; \mathrm{p}<0.05)$ higher than 
women. There was no relationship between cancer stages and dietary energy $(p>0.05)$. Conclusions: Malnutrition is common in cancer patients, low percentage of energy requirements, relationship between age and gender with dietary energy.

Keywords: Nutritional status, cancer patients, Patient-Generated Subjective Global Assessment (PG SGA).

\section{I. ĐĂT VẤN ĐỀ}

Suy dinh dưỡng (SDD) là tình trạng phổ biến ở bệnh nhân ung thư chiếm $30-85 \%$. Nguyên nhân của SDD ở người bệnh ung thư phức tạp, có thể do vị trí khối u, loại khối u, giai đoạn bênh, tác dụng phụ của điều trị, tình trạng kinh tế xã hội, triệu chứng của bênh tác động đến dinh dưỡng hoặc dinh dưỡng không đầy đủ [1].

Đánh giá tình trạng dinh dưỡng và phân tích các yếu tố liên quan đến khẩu phần ăn sẽ giúp cho công tác can thiệp dinh dưỡng kịp thời trong suốt quá trình điều trị ung thư, tăng hiệu quả điều trị [2], [6]. Xuất phát từ thực tiến trên, nghiên cứu được thực hiện với mục tiêu đánh giá thực trạng dinh dưỡng, khẩu phần ăn 24h của người bệnh ung thư tại Bệnh viện Quân y 103 và một số yễu tố liên quan đến tỷ lệ đạt mức năng lượng khẩu phần.

\section{II. ĐỐI TƯỢNG VÀ PHƯƠNG PHÁP NGHIÊN CỨU}

2.1. Đối tượng nghiên cứu. Nghiên cứu được tiến hành trên người bệnh ung thư điều trị nội trú tại Trung tâm Ung bướu và $Y$ học hạt nhân Bệnh viện Quân y 103, từ tháng 1 năm 2019 đển tháng 10 năm 2019. Tiêu chuẩn chọn đối tượng nghiên cứu: Tuổi trưởng thành ( $\geq 18$ tuổi), có đủ điều kiện sức khỏe để trả lời các câu hỏi điều tra và hoàn toàn tự nguyện tham gia và nghiên cứu. Tiêu chuẩn loại trừ: Hồ sơ bênh án không đầy đủ thông tin. Người bệnh không có khả năng trả lời các câu hỏi, không đủ minh mẫn, khó khăn trong giao tiếp.

\subsection{Phương pháp}

\section{*Thiết kế nghiên cứu:}

Nghiên cứu mô tả. Cỡ mẫu nghiên cứu được tính theo công thức sau:

$$
\mathrm{n}=\mathrm{Z}^{2}(1-\mathrm{a} / 2) \frac{\mathrm{pq}}{\mathrm{d}^{2}}
$$

Trong đó: $\mathrm{n}$ : cõ̃ mẫu; $\mathrm{p}$ : tỵ lệ bệnh nhân ung thư suy dinh dương theo PG-SGA, $p=0,517$ [6]; $\mathrm{q}=1-\mathrm{p}$; $\mathrm{d}$ : khoảng sai lệch, chọn $\mathrm{d}=7 \%=$ 0,07; a: mức ý nghĩa thống kê, $a=0,05$. Khi đó $Z^{2}(1-a / 2)=1,96$. Thay vào công thức trên ta được $\mathrm{n}=196$. Để đảm bảo đủ cõ mấu cho nghiên cứu nên đã tính dư thêm $20 \%$. Do đó, cõ̃ mẫu là 250 bênh nhân. Khi tiến hành nghiên cứu đã loại bỏ 38/250 BN do không thỏa mãn điều kiện lựa chọn, còn 212 BN đưa vào phân tích số liệu.
Chọn mẫu: Mẫu nghiên cứu được chọn mẫu thuận tiện, tất cả $\mathrm{BN}$ nằm điều trị nội trú tại bệnh viện trong thời gian tiến hành nghiên cứu và thỏa mãn tiêu chuẩn lựa chọn đều được chọn vào nghiên cứu cho tới khi đủ cỡ mẫu.

*Phương pháp thu thập và xử lý số liệu

Sử dung phiếu điều tra, cân bàn đạt tiêu chuẩn, thước dây, tham khảo hồ sơ bênh án và quyển ảnh dùng cho điều tra khẩu phần ăn của Viện dinh dưỡng năm 2014. Dựa trên biến số nghiên cứu và thử nghiệm bộ công cụ. Các thông tin thu được trên phiếu điều tra sẽ được mã hóa và xử lý bằng phần mềm thống kê y học SPSS 22.0

*Các thước đo, tiêu chuẩn đánh giá:

- Chỉ số khối cơ thể (BMI - Body Mass Index).

- Phương pháp đánh giá tình trạng dinh dưỡng người bệnh ung thư theo thang điểm PGSGA với 3 mức phân loại: PG -SGA A (dinh dưỡng tốt); PG - SGA B (SDD nhe hoặc có nguy cơ SDD); PG - SGA C (SDD nặng).

- Đánh giá khẩu phần ằn: Sử dụng bảng thành phần dinh dưỡng của thực phẩm Viêt Nam 2007 để tính trung bình năng lượng và các chất dinh dưỡng của từng bệnh nhân.

- Chỉ số hóa sinh: Chẩn đoán SDD dựa vào các chỉ số xét nghiệm sinh hóa theo Rossi.R.E. và CS (2015). Đánh giá tình trang dinh dưỡng dựa vào các chỉ số huyết học theo Thorsdottir và cs. (2005).

- Sai lệch thông tin: Tập huấn kỹ cách thức thu thâp số liệu cho điều tra viên, đặc biêt cách đánh giá dinh dưỡng bằng công cụ PG - SGA.

- Kiểm soát sai lệch lựa chọn: Định nghĩa rõ ràng đối tượng nghiên cứu căn cứ vào tiêu chuẩn chọn và tiêu chuẩn loại trừ.

\section{KẾT QUẢ NGHIÊN CỨU}

\section{1. Đặc điểm chung đôii tượng nghiên cứu}

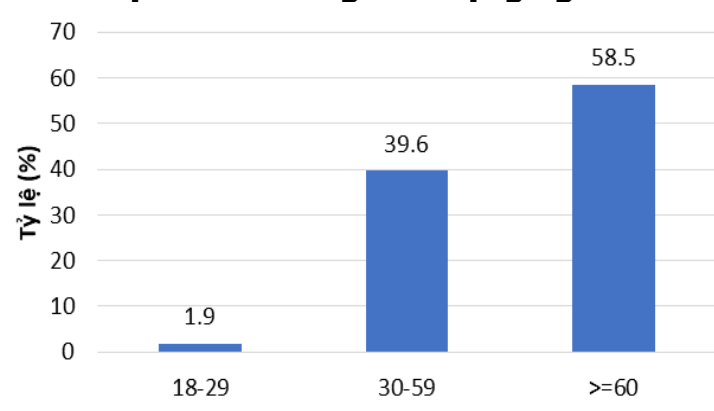

Biểu đồ 1. Phân bố tuổi của người bệnh ung thư Nhân xét: Phân bố ung thư theo các nhóm tuổi khác nhau, hay gặp ở nhóm $\geq 60$ tuổi $(58,5 \%)$ và $30-59$ tuổi $(39,6 \%)$, ít gặp ở nhóm 18-30 tuổi $(1,9 \%)$. 


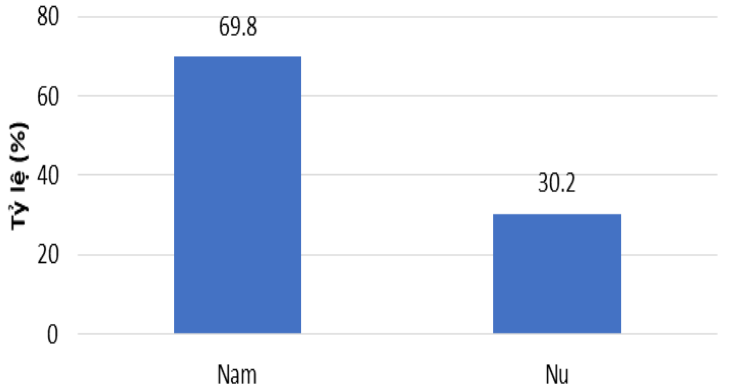

Biểu đồ 2. Phân bố giới tính của người bệnh ung thu

Nhận xét: Phân bố ung thư chủ yễu ở nam $(69,8 \%)$ so với nữ $(30,2 \%)$.

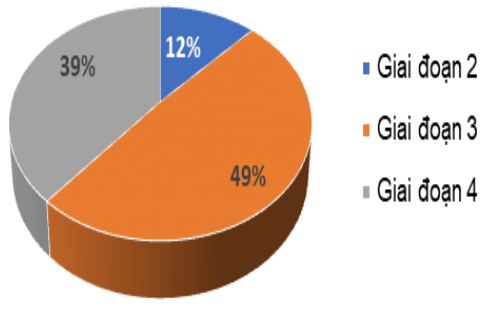

Biểu đồ 3. Phân bố giai đoạn ung thư

Nhận xét: Phần lớn người bệnh ung thư ở giai đoạn $3(49 \%)$ và giai đoạn $4(39 \%)$, giai đoạn 2 chiếm tỷ lệ thấp nhất (12\%).

3.2. Đặc điểm khẩu phân ăn của bệnh nhân ung thư

Nhận xét: So sánh tỷ lệ suy dinh dưỡng qua các phương pháp đánh giá tình trạng dinh dưỡng người bệnh ung thư dựa trên lâm sàng và cận lâm sàng cho thấy: tỷ lệ cao nhất khi đánh giá bằng phương pháp PG-SGA (91\%); sau đó đến các phương pháp đánh giá BMI $(34,4 \%)$, Lympho $(27,8 \%)$, Hemoglobin (25,9\%); tỷ lệ thấp nhất là đánh giá qua Albumin huyết thanh $(6,1 \%)$.

3.3. Giá trị dinh dưỡng khẩu phân ăn của người bệnh ung thư tại bệnh viện

Bảng 3.1. Giá trị năng lượng khẩu phân ăn trung bình cửa bệnh nhần ung thư

\begin{tabular}{|c|c|c|c|}
\hline Nhóm BN & $\begin{array}{c}\text { E KPA } \\
\text { TB } \pm \oplus L C(\text { Kcal/24h) }\end{array}$ & $\begin{array}{c}\text { NCKN } \\
\text { TB } \pm \oplus L C(\text { Kcal/24h) }\end{array}$ & $\begin{array}{l}\text { Tỷ lệ bệnh nhân } \\
\text { đạt NĆKN (\%) }\end{array}$ \\
\hline Ung thư đường tiêu hóa & $1,499.8 \pm 344.9$ & $1,835.6 \pm 249.9$ & $16.40 \%$ \\
\hline Ung thư phối & $1,594.5 \pm 414.6$ & $1,882.9 \pm 229.7$ & $21.40 \%$ \\
\hline Ung & $1,532.7 \pm 306.6$ & $1,739.7 \pm 178.0$ & $36.80 \%$ \\
\hline Ung thư khác & $1,754.6 \pm 448.1$ & $1,857.7 \pm 287.5$ & $32.90 \%$ \\
\hline Chung & $1,627.7 \pm 416.1$ & $1,848.0 \pm 256.2$ & $25.90 \%$ \\
\hline
\end{tabular}

Nhận xét: Trên thực tế, giá trị năng lượng trung bình từ KPA hàng ngày của BN K $(1,627.7 \mathrm{Kcal})$ thấp hơn so với nhu cầu khuyến nghị trung bình $(1,848.0 \mathrm{Kcal})$. Tỷ lệ đạt nhu cầu năng lượng khuyến nghị cho BN K chỉ đạt 25,9\%. Trong đó đạt cao nhất là nhóm ung thư vú $(32.90 \%)$, và thấp nhất là ung thư tiêu hóa (16.40\%).

Bảng 3.2. Giá trị protein khẩu phần ăn trung bình của bệnh nhân ung thư khi điều trị

\begin{tabular}{|c|c|c|c|}
\hline Nhóm BN & $\begin{array}{c}\text { P KPA } \\
\text { TB } \pm \text { KLC }(\mathrm{g} / 24 \mathrm{~h})\end{array}$ & $\begin{array}{c}\text { NCKN } \\
\text { TB } \pm \text { ĐLC }(\mathrm{g} / 24 \mathrm{~h})\end{array}$ & $\begin{array}{c}\text { Tỷ lệ bệnh nhân } \\
\text { đat NCKN }(\%)\end{array}$ \\
\hline Ung the & \pm 14.4 & $64.6 \pm 11.1$ & $34.50 \%$ \\
\hline Ung thư phối & $60.3 \pm 13.8$ & $63.9 \pm 10.3$ & $41.10 \%$ \\
\hline
\end{tabular}

